\title{
Effect of velocity on shoulder muscle recruitment patterns during wheelchair propulsion in nondisabled individuals: Pilot study
}

\author{
Liping Qi, PhD; ${ }^{1-2}$ James Wakeling, PhD; ${ }^{3}$ Simon Grange, PhD; ${ }^{1-2}$ Martin Ferguson-Pell, PhD $^{2^{*}}$ \\ ${ }^{1}$ ASPIRE Centre for Disability Sciences, Institute of Orthopedics and Musculoskeletal Science, University College \\ London, Brockley Hill, Stanmore, London, United Kingdom; ${ }^{2}$ Faculty of Rehabilitation Medicine, University of \\ Alberta, Edmonton, Alberta, Canada; ${ }^{3}$ Department of Biomedical Physiology and Kinesiology, Simon Fraser \\ University, Burnaby, British Columbia, Canada
}

\begin{abstract}
This study investigated how the recruitment patterns of shoulder muscles were influenced by wheelchair propulsion speed. Electromyography (EMG) activity of seven muscles was recorded with surface electrodes on 15 nondisabled subjects during wheelchair propulsion on a stationary ergometer. Kinetic data were measured by a SmartWheel. EMG total intensities were calculated to describe the muscle activation level, while the angles formed by first principal component and second principal component loading scores were calculated to describe the spectral content of EMG signals. Significant differences were observed in kinetic variables between the two testing speeds ( $p<$ $0.05)$. The EMG intensity of the tested muscles increased significantly with increased speed $(p<0.05)$. The push muscles showed a longer EMG duration, whereas the recovery muscles exhibited significantly earlier EMG onset and peak activities at the fast speed. The smaller angle values in the fast propulsion speed indicated that faster motor units were recruited to match the mechanical requirement for the faster motion. Pushing a manual wheelchair at a faster speed not only requires a higher level of propulsive muscle activity but also a higher level of recovery muscle activation.
\end{abstract}

Key words: electromyography, ergometer, fast fiber, kinetics, motor unit recruitment strategy, muscle synergy, principal component analysis, rehabilitation, slow fiber, wavelet analysis.

\section{INTRODUCTION}

People who have impaired or nonfunctional lower limbs, like persons with spinal cord injury (SCI), often rely on their ability to propel a manual wheelchair for independent mobility for several decades of their life. During this time, they expose their shoulder joints to forces for which they were not designed. As a result, the joints and soft tissues of the upper limb are subject to repeated loads as the manual wheelchair user (MWU)

\footnotetext{
Abbreviations: $\mathrm{AD}=$ anterior deltoid, $\mathrm{BB}=$ biceps brachii, $\mathrm{EMG}=$ electromyography, $\mathrm{MD}=$ middle deltoid, $\mathrm{ME}=$ mechanical effectiveness, $\mathrm{MU}=$ motor unit, $\mathrm{MVIC}=$ maximum voluntary isometric contraction, $\mathrm{MWU}=$ manual wheelchair user, $\mathrm{PCA}=$ principal component analysis, $\mathrm{PCI}=$ first principal component, $\mathrm{PCII}=$ second principal component, $\mathrm{PD}=$ posterior deltoid, $\mathrm{PM}=$ pectoralis major, $\mathrm{PO}=$ power output, $\mathrm{SCI}=$ spinal cord injury, $\mathrm{sEMG}=$ surface $\mathrm{EMG}, \mathrm{TB}=$ triceps brachii, UT = upper trapezius.

*Address all correspondence to Martin Ferguson-Pell, PhD; Faculty of Rehabilitation Medicine, 3-48 Corbett Hall, University of Alberta, Edmonton, Alberta, Canada T6G 2G4; 780-492-5991; fax: 780-492-1626.

Email: martin.ferguson-pell@ualberta.ca http://dx.doi.org/10.1682/JRRD.2011.03.0047
} 
goes about the activities of everyday life. A large amount of data now exist from various epidemiological studies linking manual wheelchair propulsion, transfers, and lifts to a variety of shoulder problems, including soft tissue injuries and degenerative joint changes [1-3]. Estimates of shoulder pain among MWUs with SCI range from 30 to 73 percent [4-5]. The high prevalence of musculoskeletal disorders of MWUs has provoked new emphasis on the study of shoulder pain with its long-term consequences.

Mobility restoration, activities of daily living, and sports for those with SCI require several different propulsion speeds. The minimum speed required to safely cross an intersection is deemed to be $1.06 \mathrm{~m} / \mathrm{s}$ [6], while the average self-selected speed is $0.8 \mathrm{~m} / \mathrm{s}$ for tetraplegia patients and $1.2 \mathrm{~m} / \mathrm{s}$ for paraplegia patients [7]. For general participation in the community, a walking speed of $1.22 \mathrm{~m} / \mathrm{s}$ would be desirable [6,8]. Propulsion speed is known to influence muscle activity and wheelchair biomechanics during wheelchair propulsion. Many studies have documented shoulder kinetics and kinematics during wheelchair propulsion at multiple speeds [3,9-11]. Shoulder joint forces and moments have been shown to increase at faster speeds [12]. Mercer et al. found that MWUs who pushed with a faster speed and loaded the pushrim more frequently were more likely to have shoulder pathology or pain [3]. Koontz et al. reported that individuals changed their shoulder movement patterns depending on how fast they propelled [11]. However, measures of kinetics and kinematics are not direct measures of muscle recruitment, and it is not possible to use these measures to infer differences in individual muscle activity for different wheelchair propulsion speeds.

A number of studies have identified that altered muscle recruitment patterns are associated with musculoskeletal disorders [13-14]. The shoulder consists of several joints that function optimally when there is precise recruitment and coordination of the muscles attached to these joints [15-16]. This precise recruitment and coordination of the muscles not only provides optimal energy transfer from the muscles to the wheelchair but also offers protection to the joints. If any particular muscle becomes too strong or too weak, the disproportionate strength or weakness of one particular muscle may disturb the muscle coordination and put the joints at risk. Hence, identifying weak components in muscle synergies and strengthening them with specific muscle training may improve the wheelchair propulsion performance and reduce the risk of injuries. On the other hand, changes in composition of muscle fiber types might be associated with muscle overuse and muscle pathologies [17]. The combined use of wavelet and principal component analysis (PCA) is a promising advanced electromyography (EMG) technique that has been successfully applied in gait [18], running [19], and cycling [20] to show that different muscle fiber types are recruited. The purpose of this study was to determine, using EMG and kinetics, the influence of the propulsion speed on the recruitment of shoulder muscles and fast and slow motor units (MUs) during wheelchair propulsion.

\section{METHODS}

\section{Participants}

Fifteen nondisabled participants (eight males, seven females; age: $30 \pm 4 \mathrm{yr}$; weight: $66 \pm 11 \mathrm{~kg}$ ) volunteered to participate in this study (Table 1). Participants had no or little experience with wheelchair use. Inclusion criteria stipulated no previous history of upper-limb pain or neuromuscular disorder. Participants were instructed not to perform any exercise for $48 \mathrm{~h}$ preceding the measurements.

\section{Surface Electromyography}

Surface EMG (sEMG) activity of upper-limb muscles was recorded using parallel-bar EMG Sensors (DE-3.1 double differential sensor, $1 \mathrm{~mm}$ in diameter and separated

Table 1.

Physical characteristics of participants.

\begin{tabular}{cccc}
\hline Subject & Sex & Age & Body Mass (kg) \\
\hline 1 & M & 31 & 63.2 \\
2 & M & 40 & 80.4 \\
3 & M & 32 & 72.3 \\
4 & M & 29 & 71.2 \\
5 & $\mathrm{~F}$ & 35 & 70.8 \\
6 & $\mathrm{~F}$ & 26 & 67.2 \\
7 & $\mathrm{~F}$ & 31 & 56.6 \\
8 & $\mathrm{M}$ & 28 & 63.7 \\
9 & $\mathrm{M}$ & 32 & 75.1 \\
10 & $\mathrm{~F}$ & 34 & 50.6 \\
11 & $\mathrm{M}$ & 26 & 87.1 \\
12 & $\mathrm{~F}$ & 25 & 53.5 \\
13 & $\mathrm{~F}$ & 27 & 46.2 \\
14 & $\mathrm{~F}$ & 26 & 57.8 \\
15 & $\mathrm{M}$ & 28 & 73.5 \\
Mean \pm SD & - & $30 \pm 4$ & $66 \pm 11$ \\
\hline F= female, M=male, SD $=$ standard deviation. \\
\hline \hline
\end{tabular}


by $10 \mathrm{~mm}$, Bagnoli ${ }^{\mathrm{TM}}$, Delsys Inc; Boston, Massachusetts). sEMG signals were detected on seven muscles - anterior, middle, and posterior portions of the deltoid $(\mathrm{AD}, \mathrm{MD}$, and $\mathrm{PD}$, respectively; sternal part of the pectoralis major (PM); upper trapezius (UT); biceps brachii (BB); and triceps brachii $(\mathrm{TB})$ - on the right shoulder after prior removal of hair and cleaning with alcohol swipes. We confirmed sensor placement by testing elevation (AD, $\mathrm{MD}$, and $\mathrm{PD}$ ), external rotation (UT and $\mathrm{PD}$ ), internal rotation (PM), and arm flexion and extension (BB and TB). The EMG signals were amplified and sampled at 2,000 Hz. The EMG was recorded with a 16-bit analogto-digital converter (PCI-6220, National Instruments Corporation; Austin, Texas).

\section{Kinetic System}

Three-dimensional forces and moments acting on the pushrim were measured using a SmartWheel (Three Rivers Inc, LLC; Mesa, Arizona). The pushrim kinetic data were collected at $240 \mathrm{~Hz}$. The kinetic system was synchronized with the EMG data by triggering the SmartWheel with a signal that was simultaneously recorded on the EMG data acquisition system.

All participants were tested in the same wheelchair (Quickie GP, Sunrise Medical; Longmont, Colorado) fitted with $56 \mathrm{~cm}$-diameter rear wheels and $13 \mathrm{~cm}$ caster wheels, $41 \mathrm{~cm}$ seat width, and $0^{\circ}$ camber. The test wheelchair was secured onto a wheelchair ergometer. The wheelchair ergometer was modeled after the dynamometer described in Koontz et al. [12,21]. The ergometer consists of two independent steel tubular rollers, one for each wheel, supported by pillow-block bearings. The bearings are mounted to steel channels. Braking force $(F)$ of roller at constant velocity with no added resistance was calculated as $F=m a$, where the roller's mass $(m)$ is $32.37 \mathrm{~kg}$; acceleration $(a)$ was calculated when the wheel was coasting down to zero $(\Delta V / \Delta t)$, where $V=$ velocity and $t=$ time. Rolling resistance depends on the weight of the subject. Power output (PO) was calculated as $\mathrm{PO}=F_{\mathrm{x}} V$, where the applied force $\left(F_{\mathrm{X}}\right)$ must balance the average rolling resistance.

\section{Procedure}

\section{Maximum Voluntary Isometric Test}

To facilitate comparison between studies, the EMG intensities were normalized by the use of a maximum voluntary isometric contraction (MVIC). A total of four muscle tests were performed following the methods described by Boettcher et al. [22] and Kelly et al. [23]. The test order was block randomized. Isometric contractions were performed by the participants with their wrist attached to a force transducer (Model LCCB-1K, OMEGA Engineering; Stamford, Connecticut) while EMG was measured simultaneously. Subjects were seated in a stable chair (not a wheelchair) during the MVIC tests.

\section{Propulsion Session}

The participants were instructed to use a semicircular propulsion pattern [24-25] as recommended by clinical practice guidelines [24]. All participants were advised to familiarize themselves with the semicircular pattern before testing. The SmartWheel was fitted to the right side of the test wheelchair. Real-time speed feedback was displayed on a monitor in front of the participant during the trials. The participants performed two trials of wheelchair propulsion, one at $0.9 \mathrm{~m} / \mathrm{s}$ and a second at $1.6 \mathrm{~m} / \mathrm{s}$ for $1 \mathrm{~min}$, with a minimum rest interval of $5 \mathrm{~min}$ between trials.

\section{Data Analysis}

The push cycle was divided into two phases: push phase and recovery phase (Figure 1) [26-27]. Ten continuous cycles recorded from the SmartWheel were used for data analysis. The kinetic variables analyzed were mean resultant force $\left(F_{\text {tot }}\right)$, mean tangential force $\left(F_{t}\right)$, mean propulsion moment $\left(M_{\mathrm{z}}\right)$, push frequency (number of pushes per second), push length in degrees (length of palm-onpalm-off, in degrees), and push time (time of individual pushes) [26]. Mechanical effectiveness (ME) was calculated by $F_{\mathrm{t}} / F_{\text {tot }}$ [28]. Percent push phase is the percentage share of the push phase in the total propulsion cycle.

A wavelet technique was applied to analyze the EMG signals [29]. Detailed description of this method can be found in previous articles [26,30-31]. All signal processing was performed using custom programs written in Mathematica (version 6.0, Wolfram Inc; Champaign, Illinois). The EMG intensity is a close approximation to the power of the signal contained within a given frequency band, and the intensity spectrum is equivalent to the power spectrum from the signals. EMG data were synchronized with kinetic data. The time base of the propulsion cycle was normalized to 100 percent to facilitate the comparison across participants (Figure 1).

PCA was used to quantitatively identify the contribution of high and low frequency content within the EMG signal. The method has been described in detail in previous articles [26,30-32]. In short, the first principal component 


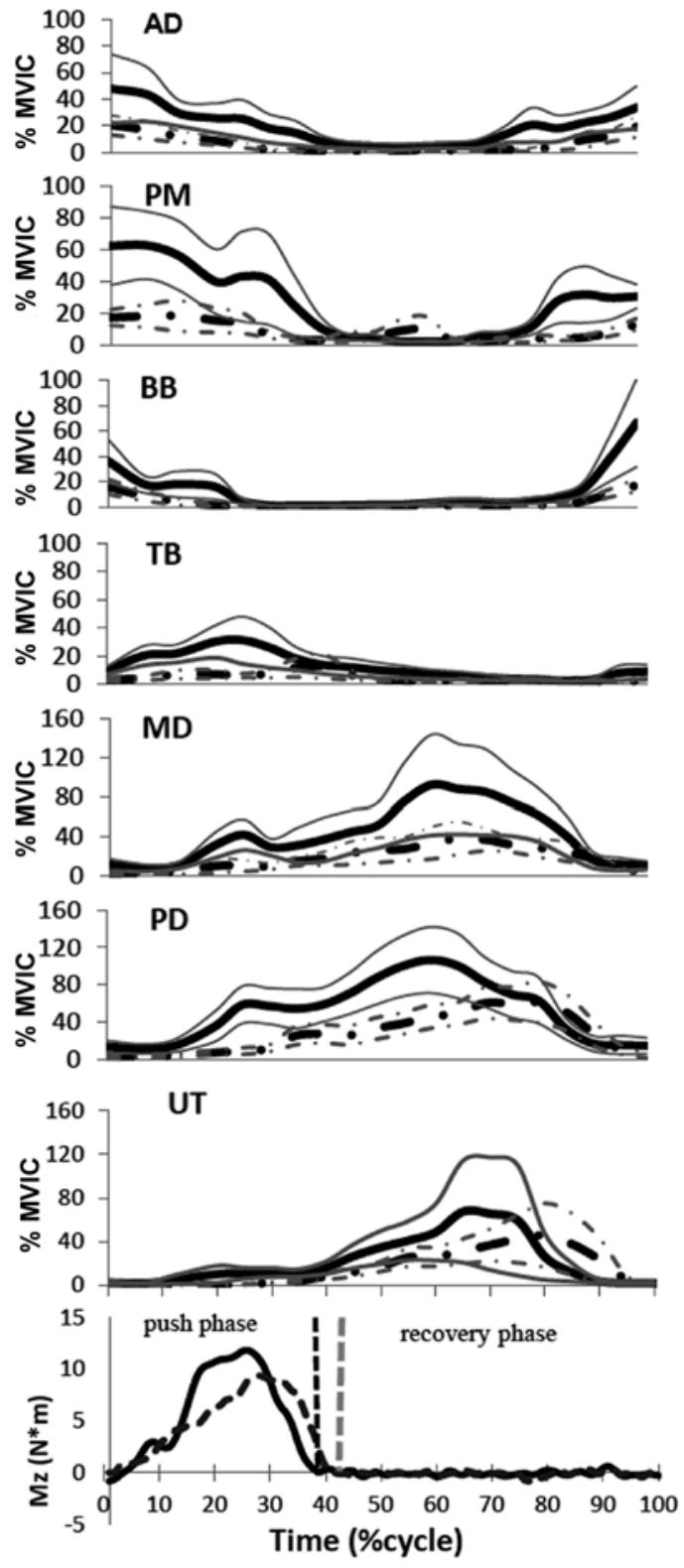

Figure 1.

Total electromyography (EMG) intensity and pushrim moment for different muscles. $y$-axis of EMG data was normalized to percentage of maximum voluntary isometric contraction (\%MVIC). $x$-axis of EMG data was normalized to percentage of propulsion cycle time and synchronized with kinetic data $\left(M_{\mathrm{z}}\right) . M_{\mathrm{z}}$ is propulsion moment. Vertical lines of $M_{z}$ represent transition between push and recovery phases. Each trace shows mean (thick line) \pm standard error of the mean (gray line). Dotted line shows data for trials at $0.9 \mathrm{~m} / \mathrm{s}$, solid black line for $1.6 \mathrm{~m} / \mathrm{s}$. Data were averaged over all subjects. $A D=$ anterior deltoid, $B B=$ biceps brachii, $M D=$ middle deltoid, $\mathrm{PD}=$ posterior deltoid, $\mathrm{PM}=$ pectoralis major, $\mathrm{TB}=$ triceps brachii, UT = upper trapezius.
(PCI) and second principal component (PCII) account for more than 80 percent of the signal. The angle $\theta$ formed between the PCI and PCII loading scores can be used to estimate the recruitment of fast and slow MUs (Figure 2). A higher $\theta$ value is associated with the recruitment of slower MUs, whereas a lower $\theta$ value is associated with the recruitment of faster MUs [33].

To determine changes in recruitment over the course of a propulsion cycle, we partitioned data from each push into 20 equal time windows and calculated mean values for each time window. PCI and PCII loading scores were calculated for each of the 20 partitioned time windows within the propulsion cycle, enabling the relative signal frequency content to be defined for different time points within the propulsion cycle.

\section{Statistical Analysis}

Statistical analysis was performed using SPSS (SPSS 16, IBM Corp; Armonk, New York). The KolmogorovSmirnov and Shapiro-Wilk tests were performed first to confirm data normality. Two-tailed paired $t$-tests were conducted to test for significant differences in kinetic performance, EMG intensity, PCI, and $\theta$ between the two testing speeds. Significant difference in the mean $\theta$ value and EMG intensity of the two speeds and propulsion time window were analyzed within each muscle by using

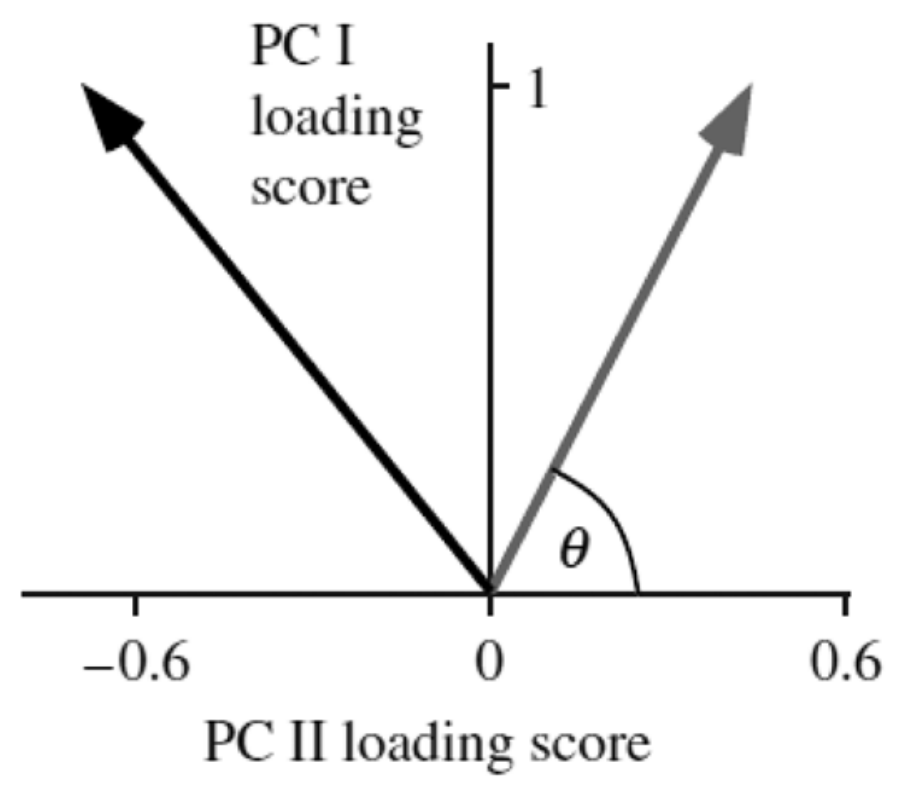

Figure 2.

Angle $\theta$ is defined by direction of first principal component $(\mathrm{PCl})$ and second principal component (PCII) loading score vector. 
full-factorial general linear model analysis of variance, with speed and time windows defined as fixed factors. In all statistical analysis, results were considered to be significant if the alpha error estimate was $p<0.05$. All data are reported in the text as mean \pm standard deviation while the results are graphed in each figure as mean \pm standard error of the mean.

\section{RESULTS}

\section{Kinetics}

The PO is $29.2 \mathrm{~W}$ at the speed of $0.9 \mathrm{~m} / \mathrm{s}$ and $51.9 \mathrm{~W}$ at the speed of $1.6 \mathrm{~m} / \mathrm{s} . F_{\text {tot }}, F_{\mathrm{t}}, M_{\mathrm{z}}$, push length, push time, push frequency, $\mathrm{ME}$, and percent push phase from the two testing speeds are shown in Table 2. These variables significantly differed between the two testing speeds, except for ME.

\section{Electromyography Activity}

The average timing of EMG activity of the seven muscles during wheelchair propulsion is shown in Table 3. Total EMG intensity and pushrim propulsion moment during each propulsion stroke for the different muscles are displayed in Figure 1. Principal component loading scores for PCI and PCII from the seven muscles are shown in Figure 3.

$\mathrm{AD}, \mathrm{PM}, \mathrm{BB}$, and $\mathrm{TB}$ are mainly active during the push phase, so they are defined as push muscles; UT, $\mathrm{MD}$, and PD had their main EMG activities during the recovery phase, so they are defined as recovery muscles. The EMG duration of AD between the two speeds was significantly different; the faster speed had a significantly longer EMG duration than the slow speed $(p<0.05)$. The EMG onset of UT was significantly earlier in the fast speed $(p<0.05)$, whereas the cessation of EMG was significantly later in the fast speed $(p<0.05)$. The peak activities

Table 2.

Kinetic parameters for two testing speeds of wheelchair propulsion. Data reported as mean \pm standard deviation.

\begin{tabular}{|c|c|c|c|c|c|}
\hline \multirow{2}{*}{ Kinetic Parameter } & \multicolumn{2}{|c|}{ Speed (m/s) } & \multicolumn{2}{|c|}{ 95\% Confidence Interval } & \multirow{2}{*}{$\begin{array}{l}\text { Significance } \\
\text { (two-tailed) }\end{array}$} \\
\hline & 0.9 & 1.6 & Lower & Upper & \\
\hline$\overline{\operatorname{Mean}} F_{\text {tot }}(\mathrm{N})$ & $33.8 \pm 9.9$ & $45.8 \pm 11.6$ & 7.20 & 16.90 & 0.001 \\
\hline Mean $M_{\mathrm{Z}}(\mathrm{Nm})$ & $6.2 \pm 1.1$ & $8.3 \pm 1.0$ & 1.40 & 2.80 & 0.001 \\
\hline Push Length $\left(^{\circ}\right)$ & $60.1 \pm 7.3$ & $64.2 \pm 4.9$ & 0.22 & 7.95 & 0.04 \\
\hline Push Time (s) & $1.1 \pm 0.2$ & $0.9 \pm 0.1$ & -0.30 & -0.10 & 0.001 \\
\hline Mechanical Effectiveness & $0.7 \pm 0.1$ & $0.7 \pm 0.1$ & -0.05 & 0.04 & 0.75 \\
\hline$\%$ Push Phase & $42.9 \pm 6.4$ & $35.3 \pm 6.6$ & -10.20 & -2.50 & 0.03 \\
\hline
\end{tabular}

$\%$ push phase $=$ percentage share of push phase in total propulsion cycle (data averaged over all subjects), mean $F_{\mathrm{t}}=$ average tangential force, mean $F_{\text {tot }}=$ average total force, mean $M_{\mathrm{z}}=$ average propulsion moment, mechanical effectiveness = ratio of $F_{\mathrm{t}} / F_{\text {tot }}$, push frequency = number of pushes per second, push length $=$ length of palm-on-palm-off, push time $=$ time of individual pushes.

Table 3.

Timing of electromyography activity of wheelchair propulsion at two speeds $(0.9$ and $1.6 \mathrm{~m} / \mathrm{s})$. Data reported as mean \pm standard deviation.

\begin{tabular}{|c|c|c|c|c|c|c|c|c|}
\hline \multirow{2}{*}{ Muscle } & \multicolumn{2}{|c|}{ Onset (\% cycle) } & \multicolumn{2}{|c|}{ Cessation (\% cycle) } & \multicolumn{2}{|c|}{ Duration (\% cycle) } & \multicolumn{2}{|c|}{ Peak (\% cycle) } \\
\hline & $0.9 \mathrm{~m} / \mathrm{s}$ & $1.6 \mathrm{~m} / \mathrm{s}$ & $0.9 \mathrm{~m} / \mathrm{s}$ & $1.6 \mathrm{~m} / \mathrm{s}$ & $0.9 \mathrm{~m} / \mathrm{s}$ & $1.6 \mathrm{~m} / \mathrm{s}$ & $0.9 \mathrm{~m} / \mathrm{s}$ & $1.6 \mathrm{~m} / \mathrm{s}$ \\
\hline $\mathrm{AD}$ & $89 \pm 8$ & $80 \pm 6$ & $28 \pm 6$ & $31 \pm 11$ & $40 \pm 9^{*}$ & $52 \pm 12^{*}$ & $10 \pm 8$ & $11 \pm 8$ \\
\hline PM & $86 \pm 8$ & $85 \pm 7$ & $31 \pm 10$ & $34 \pm 9$ & $45 \pm 8$ & $50 \pm 11$ & $19 \pm 22$ & $33 \pm 37$ \\
\hline $\mathrm{BB}$ & $84 \pm 14$ & $78 \pm 17$ & $18 \pm 7$ & $18 \pm 7$ & $33 \pm 13$ & $40 \pm 18$ & $93 \pm 10$ & $93 \pm 11$ \\
\hline TB & $97 \pm 3$ & $92 \pm 9$ & $43 \pm 10$ & $40 \pm 10$ & $45 \pm 8$ & $48 \pm 12$ & $22 \pm 13$ & $14 \pm 7$ \\
\hline UT & $35 \pm 9^{*}$ & $27 \pm 7^{*}$ & $92 \pm 4^{*}$ & $87 \pm 7^{*}$ & $55 \pm 10^{*}$ & $59 \pm 8^{*}$ & $68 \pm 10^{*}$ & $58 \pm 11^{*}$ \\
\hline MD & $26 \pm 5^{*}$ & $18 \pm 7^{*}$ & $92 \pm 4$ & $88 \pm 5$ & $66 \pm 8$ & $70 \pm 10$ & $71 \pm 11^{*}$ & $50 \pm 20^{*}$ \\
\hline PD & $30 \pm 7^{*}$ & $20 \pm 9^{*}$ & $93 \pm 4$ & $89 \pm 4$ & $62 \pm 8$ & $68 \pm 11$ & $72 \pm 12^{*}$ & $54 \pm 18^{*}$ \\
\hline
\end{tabular}

*Significant difference for $p<0.05$, data averaged over all subjects.

$\mathrm{AD}=$ anterior deltoid, $\mathrm{BB}=$ biceps brachii, $\mathrm{MD}=$ middle deltoid, $\mathrm{PD}=$ posterior deltoid, $\mathrm{PM}=$ pectoralis major, $\mathrm{TB}=$ triceps brachii, $\mathrm{UT}=$ upper trapezius. 
of EMG occurred significantly earlier in the fast speed than in the slow speed in UT $(p<0.05)$. The EMG onset of MD and PD for the fast speed was significantly earlier than for the slow speed $(p<0.05)$. The peak activities of EMG for the fast speed in MD and PD were significantly different between testing speeds $(p<0.01)$ (Table 2). The peak activities of MD occurred significantly earlier in the fast speed than the slow speed $(p<0.01)$.

EMG intensity and PCI loading scores for the fast speed were significantly higher than for the slow speed in all tested muscles (all $p<0.01$ ). The $\theta$ values were significantly different between the two speeds in BB and TB $(p<0.01)$. The $\theta$ values did not differ between speeds for other muscles; it did differ between time windows, showing that $\theta$ differed significantly over the course of propulsion (all $p<0.01$ ) (Figure 3). Compared with the slow speed, the fast speed PCI-PCII loop of all the tested muscles was characterized by relatively more positive PCII loading scores, represented by the smaller $\theta$ values (Figure 3 ).

\section{DISCUSSION}

Kinetic data showed a significantly shorter percent push phase in the fast speed condition, which was consistent with Koontz et al.'s study of shoulder kinematics and kinetics during two speeds of wheelchair propulsion [11]. EMG duration of push muscles was longer at the fast speed than at the slow speed, which is associated with earlier onset and later cessation. Mulroy et al. reported that the longer duration of PM in the push phase may prevent upward displacement of the humeral head in the MWU with cervical 7-8 tetraplegia [34]. The prolonged and higher activities of the push muscles may contribute to more propulsive force to meet the high mechanical demand during fast-speed wheelchair propulsion. As for the recovery muscles- $\mathrm{MD}, \mathrm{PD}$, and UT - their EMG onset and peak activity were significantly earlier in the fast speed than the slow speed. This may indicate a compensatory hastening from early recovery phase to late push phase stemming, in all likelihood from the MWU's effort to improve propulsion velocity. The higher EMG intensities of the recovery muscles at the fast speed condition may be associated with rapid movement in the recovery phase.

Fast and slow muscle fibers vary in their mechanical and energetic properties. Slower muscle fibers are used to power slow- and medium-speed movements, while both slow and fast fibers are used during rapid movement [35]. The loops described by the PCI-PCII loading scores of the seven muscles were characterized by smaller $\theta$ values for the faster propulsion speeds (Figure 3). This may indicate that a greater proportion of fast MUs were recruited to meet the mechanical requirements of the faster motion. Studies of the fiber-type composition show that the deltoid muscles and UT muscles have a high proportion of slow fibers [36]. The high proportion of slow fibers in these muscles is associated with their roles in postural maintenance and shoulder joint stabilization. The PD had a particularly high average slow-fiber proportion of 56 percent [36]. During the slow speed test, the larger $\theta$ values were recorded in the PD muscle, reflecting the predominantly slow population of MUs within this muscle.

The study of wheelchair propulsion is complicated by the large variability in functionality among the disabled population. Attempts to study muscle activation in MWUs would likely result in large inconsistencies in activation patterns. To overcome the inherent problem of the considerable heterogeneity of MWUs, we recruited non-wheelchair users in the present study, because they would be equally well trained or untrained for all tested conditions and, obviously, would be physically quite homogeneous [37]. The SmartWheel weighs $4.9 \mathrm{~kg}$, and one regular wheel $(1.9 \mathrm{~kg})$ was placed on the left hand side. Since the test wheelchair was secured on the ergometer, the wheelchair could not deviate from its path as a result of higher rolling resistance of the heavier SmartWheel. So, on the ergometer wheelchair, propulsion is not affected by uneven wheel weights. We adopted the semicircular stroke technique to propel the wheelchair during data collection. This technique is recommended by the clinical practice guideline based on the results of Boninger et al.'s study. [25]. The semicircular technique is used widely in experienced wheelchair users, while nonusers implemented the arcing technique [38]. Results gained from studies with nondisabled subjects demonstrated the validity and reliability of EMG data in the measurement of muscle activity; the findings of the present study are certainly in-line with earlier research [3940]. The level and timing of muscle recruitment in people who actually need to use a wheelchair are bound to show considerable variations depending on the type and level of each individual's injury [34]. Although the results may not be completely transferable to people with SCI, ultimately the aim is to be able to map the normal ranges for each of the muscles in the synergistic groups and detect when 

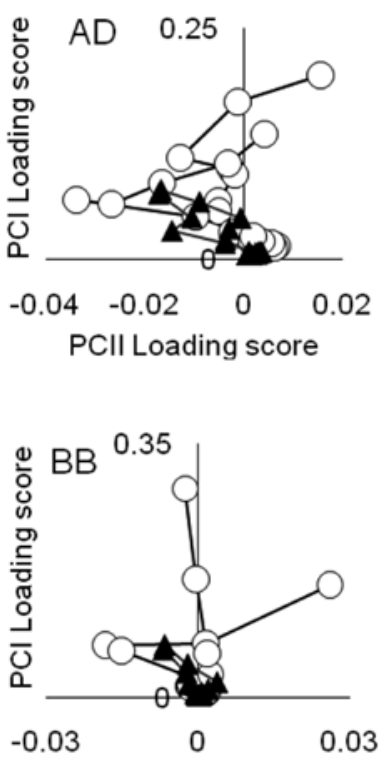

PCII Loading score
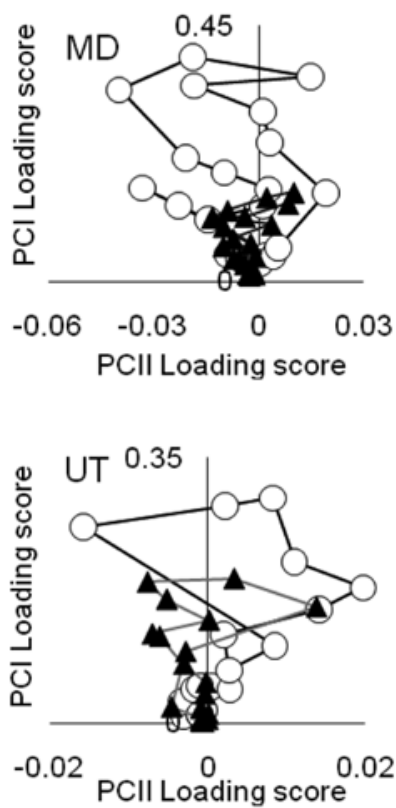

Figure 3.

Principal component loading scores for first principal component $(\mathrm{PCl})$ and second principal component (PCII) from different shoulder muscles during wheelchair propulsion at slow speed (solid triangle) and fast speed (open circle). The 20 points on each graph represent 20 time windows within each propulsion cycle. Data were averaged over all subjects. $A D=$ anterior deltoid, $\mathrm{BB}=$ biceps brachii, $\mathrm{MD}=$ middle deltoid, $\mathrm{PD}=$ posterior deltoid, $\mathrm{PM}=$ pectoralis major, $\mathrm{TB}=$ triceps brachii, UT = upper trapezius. users vary from the accepted and/or recognized patterns. This may provide an early indication of the change to a diseased state, e.g., impairment or progressive neurological condition such as multiple sclerosis, or the ability to monitor rehabilitation for the biofeedback adoption of "good," i.e., protective, learning behaviors.

\section{CONCLUSIONS}

The present study shows important differences in the EMG activity of superficial shoulder muscles between the two testing speeds during wheelchair propulsion. There were significant changes in the average timing of shoulder activity during the two testing speeds of wheelchair propulsion. The fast speed required higher activity levels in the shoulder muscles than did the slow speed. The smaller $\theta$ values in some of the windows from the fast propulsion cycle suggest that a greater proportion of fast MUs may have been recruited during rapid movement. We aim to provide wheelchair users with a performance feedback system; such a system may lead to better prevention of pain or overuse of the upper limbs for MWUs.

\section{ACKNOWLEDGMENTS}

\section{Author Contributions:}

Study concept and design: L. Qi, J. Wakeling, M. Ferguson-Pell. Acquisition of data: L. Qi, M. Ferguson-Pell.

Analysis and interpretation of data: L. Qi, J. Wakeling.

Drafting of manuscript: L. Qi, J. Wakeling, S. Grange, M. Ferguson-Pell. Critical revision of manuscript for important intellectual content:

L. Qi, J. Wakeling, S. Grange, M. Ferguson-Pell.

Statistical analysis: L. Qi.

Obtained funding: L. Qi, M. Ferguson-Pell.

Administrative, technical, or material support: L. Qi, M. Ferguson-Pell. Study supervision: J. Wakeling, S. Grange, M. Ferguson-Pell.

Financial Disclosures: The authors have declared that no competing interests exist.

Funding/Support: This material was based on work supported by a Dorothy Hodgkin Postgraduate Award, Engineering Physical Sciences Research Council, United Kingdom, with support from the Royal National Orthopedic Hospital Special Trustees.

Additional Contributions: We thank Artur Bohnet for proofreading. Institutional Review: All participants gave their informed consent in accordance with the procedures approved by the University of Alberta Research Ethics Committee.

Participant Follow-Up: The authors do not plan to inform participants of the publication of this study because contact information is unavailable. 


\section{REFERENCES}

1. Curtis KA, Drysdale GA, Lanza RD, Kolber M, Vitolo RS, West R. Shoulder pain in wheelchair users with tetraplegia and paraplegia. Arch Phys Med Rehabil. 1999;80(4):453-57. [PMID:10206610] http://dx.doi.org/10.1016/S0003-9993(99)90285-X

2. Jain NB, Higgins LD, Katz JN, Garshick E. Association of shoulder pain with the use of mobility devices in persons with chronic spinal cord injury. PM R. 2010;2(10):896-900. [PMID:20970758]

http://dx.doi.org/10.1016/j.pmrj.2010.05.004

3. Mercer JL, Boninger M, Koontz A, Ren D, Dyson-Hudson T, Cooper R. Shoulder joint kinetics and pathology in manual wheelchair users. Clin Biomech (Bristol, Avon). 2006; 21(8):781-89. [PMID:16808992]

http://dx.doi.org/10.1016/j.clinbiomech.2006.04.010

4. Pentland WE, Twomey LT. The weight-bearing upper extremity in women with long term paraplegia. Paraplegia. 1991;29(8):521-30. [PMID:1775358] http://dx.doi.org/10.1038/sc.1991.75

5. Ballinger DA, Rintala DH, Hart KA. The relation of shoulder pain and range-of-motion problems to functional limitations, disability, and perceived health of men with spinal cord injury: a multifaceted longitudinal study. Arch Phys Med Rehabil. 2000;81(12):1575-81.

[PMID:11128892]

http://dx.doi.org/10.1053/apmr.2000.18216

6. Cowan RE, Boninger ML, Sawatzky BJ, Mazoyer BD, Cooper RA. Preliminary outcomes of the SmartWheel Users' Group database: a proposed framework for clinicians to objectively evaluate manual wheelchair propulsion. Arch Phys Med Rehabil. 2008;89(2):260-68. [PMID:18226649] http://dx.doi.org/10.1016/j.apmr.2007.08.141

7. Beekman CE, Miller-Porter L, Schoneberger M. Energy cost of propulsion in standard and ultralight wheelchairs in people with spinal cord injuries. Phys Ther. 1999;79(2): 146-58. [PMID:10029055]

8. Robinett CS, Vondran MA. Functional ambulation velocity and distance requirements in rural and urban communities. A clinical report. Phys Ther. 1988;68(9):1371-73. [PMID:3420171]

9. Kulig K, Rao SS, Mulroy SJ, Newsam CJ, Gronley JK, Bontrager EL, Perry J. Shoulder joint kinetics during the push phase of wheelchair propulsion. Clin Orthop Relat Res. 1998;(354):132-43. [PMID:9755772] http://dx.doi.org/10.1097/00003086-199809000-00016

10. Mulroy SJ, Newsam CJ, Gutierrez DD, Requejo P, Gronley JK, Haubert LL, Perry J. Effect of fore-aft seat position on shoulder demands during wheelchair propulsion: part 1. A kinetic analysis. J Spinal Cord Med. 2005;28(3):214-21. [PMID:16048139]

11. Koontz AM, Cooper RA, Boninger ML, Souza AL, Fay BT. Shoulder kinematics and kinetics during two speeds of wheelchair propulsion. J Rehabil Res Dev. 2002;39(6): 635-49. [PMID:17943666]

12. Collinger JL, Boninger ML, Koontz AM, Price R, Sisto SA, Tolerico ML, Cooper RA. Shoulder biomechanics during the push phase of wheelchair propulsion: a multisite study of persons with paraplegia. Arch Phys Med Rehabil. 2008;89(4):667-76. [PMID:18373997]

http://dx.doi.org/10.1016/j.apmr.2007.09.052

13. Madeleine P, Lundager B, Voigt M, Arendt-Nielsen L. Shoulder muscle co-ordination during chronic and acute experimental neck-shoulder pain. An occupational pain study. Eur J Appl Physiol Occup Physiol. 1999;79(2):127-40. [PMID:10029333] http://dx.doi.org/10.1007/s004210050486

14. Bonacci J, Chapman A, Blanch P, Vicenzino B. Neuromuscular adaptations to training, injury and passive interventions: implications for running economy. Sports Med. 2009;39(11):903-21. [PMID:19827859] http://dx.doi.org/10.2165/11317850-000000000-00000

15. An KN. Muscle force and its role in joint dynamic stability. Clin Orthop Relat Res. 2002;403(Suppl):S37-42.

[PMID:12394451]

http://dx.doi.org/10.1097/00003086-200210001-00005

16. Veeger HE, van der Helm FC. Shoulder function: the perfect compromise between mobility and stability. J Biomech. 2007;40(10):2119-29. [PMID:17222853]

http://dx.doi.org/10.1016/j.jbiomech.2006.10.016

17. Dennett X, Fry HJ. Overuse syndrome: a muscle biopsy study. Lancet. 1988;1(8591):905-8. [PMID:2895831] http://dx.doi.org/10.1016/S0140-6736(88)91714-X

18. Wakeling JM, Kaya M, Temple GK, Johnston IA, Herzog W. Determining patterns of motor recruitment during locomotion. J Exp Biol. 2002;205(Pt 3):359-69. [PMID:11854372]

19. Neptune RR, McGowan CP, Fiandt JM. The influence of muscle physiology and advanced technology on sports performance. Annu Rev Biomed Eng. 2009;11:81-107. [PMID:19400707] http://dx.doi.org/10.1146/annurev-bioeng-061008-124941

20. Wakeling JM, Uehli K, Rozitis AI. Muscle fibre recruitment can respond to the mechanics of the muscle contraction. J R Soc Interface. 2006;3(9):533-44. [PMID:16849250] http://dx.doi.org/10.1098/rsif.2006.0113

21. Koontz AM, Yang Y, Price R, Tolerico ML, DiGiovine CP, Sisto SA, Cooper RA, Boninger ML. Multisite comparison of wheelchair propulsion kinetics in persons with paraplegia. J Rehabil Res Dev. 2007;44(3):449-58. [PMID:18247241] http://dx.doi.org/10.1682/JRRD.2006.05.0048

22. Boettcher CE, Ginn KA, Cathers I. Standard maximum isometric voluntary contraction tests for normalizing shoulder muscle EMG. J Orthop Res. 2008;26(12):1591-97.

[PMID:18528827]

http://dx.doi.org/10.1002/jor.20675 
23. Kelly BT, Kadrmas WR, Kirkendall DT, Speer KP. Optimal normalization tests for shoulder muscle activation: an electromyographic study. J Orthop Res. 1996;14(4):647-53. [PMID:8764876] http://dx.doi.org/10.1002/jor.1100140421

24. Boninger ML, Koontz AM, Sisto SA, Dyson-Hudson TA, Chang M, Price R, Cooper RA. Pushrim biomechanics and injury prevention in spinal cord injury: recommendations based on CULP-SCI investigations. J Rehabil Res Dev. 2005;42(3 Suppl 1):9-19. [PMID:16195959]

http://dx.doi.org/10.1682/JRRD.2004.08.0103

25. Boninger ML, Souza AL, Cooper RA, Fitzgerald SG, Koontz AM, Fay BT. Propulsion patterns and pushrim biomechanics in manual wheelchair propulsion. Arch Phys Med Rehabil. 2002;83(5):718-23. [PMID:11994814] http://dx.doi.org/10.1053/apmr.2002.32455

26. Qi L, Wakeling J, Grange S, Ferguson-Pell M. Changes in surface electromyography signals and kinetics associated with progression of fatigue at two speeds during wheelchair propulsion. J Rehabil Res Dev. 2012;49(1):23-34. [PMID:22492335] http://dx.doi.org/10.1682/JRRD.2011.01.0009

27. Boninger ML, Cooper RA, Robertson RN, Shimada SD. Three-dimensional pushrim forces during two speeds of wheelchair propulsion. Am J Phys Med Rehabil. 1997; 76(5):420-26. [PMID:9354497] http://dx.doi.org/10.1097/00002060-199709000-00013

28. Cooper RA, Robertson RN, VanSickle DP, Boninger ML, Shimada SD. Methods for determining three-dimensional wheelchair pushrim forces and moments: a technical note. J Rehabil Res Dev. 1997;34(2):162-70. [PMID:9108343]

29 . von Tscharner V. Intensity analysis in time-frequency space of surface myoelectric signals by wavelets of specified resolution. J Electromyogr Kinesiol. 2000;10(6):433-45.

[PMID:11102846] http://dx.doi.org/10.1016/S1050-6411(00)00030-4

30. Wakeling JM, Rozitis AI. Spectral properties of myoelectric signals from different motor units in the leg extensor muscles. J Exp Biol. 2004;207(Pt 14):2519-28. [PMID:15184523] http://dx.doi.org/10.1242/jeb.01042

31. Qi L, Wakeling JM, Green A, Lambrecht K, Ferguson-Pell M. Spectral properties of electromyographic and mechanomyographic signals during isometric ramp and step contractions in biceps brachii. J Electromyogr Kinesiol. 2011;21(1):128-35. [PMID:21067944] http://dx.doi.org/10.1016/j.jelekin.2010.09.006

32. von Tscharner V. Time-frequency and principal-component methods for the analysis of EMGs recorded during a mildly fatiguing exercise on a cycle ergometer. J Electromyogr Kinesiol. 2002;12(6):479-92. [PMID:12435545] http://dx.doi.org/10.1016/S1050-6411(02)00005-6

33. Wakeling JM. Patterns of motor recruitment can be determined using surface EMG. J Electromyogr Kinesiol.
2009;19(2):199-207. [PMID:18029198]

http://dx.doi.org/10.1016/j.jelekin.2007.09.006

34. Mulroy SJ, Farrokhi S, Newsam CJ, Perry J. Effects of spinal cord injury level on the activity of shoulder muscles during wheelchair propulsion: an electromyographic study. Arch Phys Med Rehabil. 2004;85(6):925-34. [PMID:15179646] http://dx.doi.org/10.1016/j.apmr.2003.08.090

35. Jayne BC, Lauder GV. How swimming fish use slow and fast muscle fibers: implications for models of vertebrate muscle recruitment. J Comp Physiol A. 1994;175(1):123-31. [PMID:8083846] http://dx.doi.org/10.1007/BF00217443

36. Srinivasan RC, Lungren MP, Langenderfer JE, Hughes RE. Fiber type composition and maximum shortening velocity of muscles crossing the human shoulder. Clin Anat. 2007;20(2):144-49. [PMID:16795030] http://dx.doi.org/10.1002/ca.20349

37. van der Woude LH, Veeger HE, Dallmeijer AJ, Janssen TW, Rozendaal LA. Biomechanics and physiology in active manual wheelchair propulsion. Med Eng Phys. 2001; 23(10):713-33. [PMID:11801413] http://dx.doi.org/10.1016/S1350-4533(01)00083-2

38. Chou YL, Su FC, An KN, Lu JW. Application of motion analysis system in analyzing wheelchair propulsion. Chin J Med Biol Eng. 1991;11:173-77.

39. Mulroy SJ, Gronley JK, Newsam CJ, Perry J. Electromyographic activity of shoulder muscles during wheelchair propulsion by paraplegic persons. Arch Phys Med Rehabil. 1996;77(2):187-93. [PMID:8607745] http://dx.doi.org/10.1016/S0003-9993(96)90166-5

40. Dubowsky SR, Sisto SA, Langrana NA. Comparison of kinematics, kinetics, and EMG throughout wheelchair propulsion in able-bodied and persons with paraplegia: an integrative approach. J Biomech Eng. 2009;131(2):021015. [PMID:19102574]

http://dx.doi.org/10.1115/1.2900726

Submitted for publication March 18, 2011. Accepted in revised form May 1, 2012.

This article and any supplementary material should be cited as follows:

Qi L, Wakeling J, Grange S, Ferguson-Pell M. Effect of velocity on shoulder muscle recruitment patterns during wheelchair propulsion in nondisabled individuals: Pilot study. J Rehabil Res Dev. 2012;49(10):1527-36. http://dx.doi.org/10.1682/JRRD.2011.03.0047

ResearcherID: Martin Ferguson-Pell, PhD: A-2326-2012.

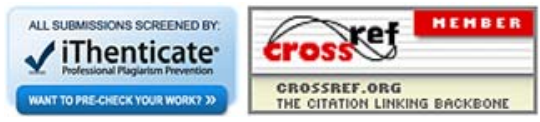


